\title{
The Impact of Storytelling on Improving Social Problems, Aggressive Behaviors, and Law-Breaking Behaviors of Primary School Children
}

Iranian Evolutionary and Educational Psychology Journal June 2020: 81-88 (C) University of Hormozgan Publication 2020 DOI: 10.29252/ieepj.2.2.81 http://ieepj.hormozgan.ac.ir

\section{Moosa Javdan ${ }^{1 *}, Z^{*}$ krollah Morovati²}

\begin{abstract}
This article focuses on effect of storytelling on improving emotional-behavioral issues such as social problems, aggressive behavior, and rule of law breaking behavior among male and female elementary school children. This is an experimental study on 68 students studying at an elementary school in one of cities of Iran in the academic year 2017-2018. Then the parent version of the Child Behavior Checklist (CBCL) was completed purposively to select 30 students with the highest scores. They were then randomly divided equally into the experimental and control groups (15 participants per group). The experimental group received fifteen 60-minute sessions taught by two teachers experienced in storytelling. When the storytelling period was over, the CBCL was given to the parents and teachers who had first completed it. The multivariate analysis of covariance (MANCOVA) was employed to analyze the data in SPSS 23. According to the results, there was only a significant difference between the experimental and control group in rule of law breaking behavior at the end of the storytelling sessions based on the assessment made by parents and teachers. Regarding social problems and aggressive behavior, there was no significant difference between the two groups. In addition, analysis of the partial eta squared $\left(\eta^{2}\right)$ values showed that storytelling explained $13 \%$ of variance of the rule of law breaking behavior.
\end{abstract} Keywords: storytelling, behavioral problems, children, elementary school, social skills.

\section{Introduction}

The first stages of a person's life are the most important periods for improving, modifying, and changing behavior. The acquisition of social and life skills can greatly prevent the emergence of behavioral, emotional, and psychosocial problems in children. It can also increase their self-awareness and self-control levels. Research shows that many children suffer from various problems in establishing social relationships, adapting to environmental conditions, and displaying self-care, self-control, and emotion control behavior, and thereby require training (Nasirzadeh \& Roshan, 2010).

Children are generally unwilling to attend therapeutic or training sessions; therefore, alternative methods such as play therapy, storytelling, and role-playing should be employed. At the same time, parents may be unaware of the real causes of their children's maladaptive behavior and behavioral disorders; thus, they may destroy children's characters through aggressive behavior. In such families, parents' aggressive behavior will

1. Faculty Member, University of Hormozgan, Department of Counseling and Psychology, Research Center for Educational and Behavioral Sciences, Bandar Abbas, Iran

*Corresponding author email: javdan@hormozgan.ac.ir

2. Department of Psychology, Faculty of Humanities, University of Zanjan, Zanjan, Iran 
be passed on to their children who may even continue their aggressive and rule of rule breaking behavior later in life during adolescence and adulthood as well (Musavi \& Hejazi, 2016).

This group of children may find it difficult to establish social interactions with peers and others. Storytelling sessions and programs provide these children with great opportunities to establish positive and dynamic relationships with others, gain positive experiences, and increase their awareness of positive social interactions and relationships. The feedback on positive interactions received after attending storytelling programs boost children's confidence and improve their perception, creativity, and problem-solving skills. Stories and tales can convey positive experiences to children and replace their irrational beliefs, notions, and insights with positive thinking, optimism, and rational-logical understanding. This process can substantially improve children's intellectual and behavioral characters and help them establish constructive and dynamic interactions with their living environment. A child who receives positive feedback from others after displaying proper behavior will no longer be interested in the rule of law breaking and anti-social behavior (Rozdar, Naziri \& Hosseini, 2014). As a living, objective, tangible, and real intervention, storytelling helps us discover the mysterious world of children.

By attending storytelling sessions and programs, children can put themselves into their favorite character's shoes and play the role of heroes in their minds. Listening skill is developed properly during these programs. As children focus completely on a story to which they are listening, they may adjust their dreams and aspirations with the story and hope that they can find amazing paths to their goals (Oduolowu \& Oluwakemi, 2014). Nasirzadeh and Roshan (2010) conducted a study on the effect of storytelling on children's aggression levels and concluded that their method reduced signs of aggression in children. Aggressive children have difficulties empathizing with their peers and thus show resistance to correction and behavior change. These children often display defiant behavior making them more impenetrable to direct methods of correction such as counseling, advice, guidance, threat, and punishment (Wright, Diener, \& Kemp, 2013). However, stories penetrate children's personality traits indirectly by strengthening their emotions and increasing their sense of self-efficacy. Stories also encourage them to copy a protagonist's actions and behavior. Therefore, many children may gradually rethink their behavior and try to control them.

In a study conducted by Roshan Chesli (2012) on children with oppositional defiant disorder (ODD), it was found that participation in storytelling sessions and programs mitigated children's behavioral problems to some extent. Undoubtedly, children with ODD are exposed to many failures in their interpersonal relationships as well as academic and social performance due to their disobedience, rebelliousness, low tolerance threshold, and depressed moods. If these children are left untreated, they will become anti-social and aggressive people; it will be very difficult to treat them during adolescence and adulthood (Sylvers, Brennan, \& Lilienfeld, 2011). Since these children have poor social skills, they may also experience feelings of rejection and humiliation, which can further exacerbate their communication and social problems.

In their study on the effect of storytelling on children's social skills, Abaresi and Temuri (2015) observed that teaching social skills reduced children's behavioral problems effectively and encouraged them to observe social rules and respect others. Research reveals that children with emotional and behavioral disorders often provoke their teachers, peers and classmates, a situation which can lead to quarrels and fights (Gamarigivi \& Khoshnoodnia, 2016) Therefore, storytelling can be used as a great intstrument and effective intervention for encouraging these children to establish positive relationships with others. In addition, storytelling improves 
children's verbal skills and helps them settle their interpersonal disagreements peacefully through interactive dialogues.

In general, several studies have confirmed the effect of storytelling on mitigating behavioral problems (Gonçalves, Voos, Almeida, \& Caromano, 2017), increasing social interactions (Watts, 2008), improving social skills, resolving behavioral problems (Roshan Chesli, 2012), preventing ODD (Fallahnejad, Kazemi, \& Pezeshk, 2018), reducing adolescents' disorders (YavandHasani, Farahbakhsh, \& ShafiAbadi, 2014), and increasing children's adaptability (Margalit, 2010).

Given the effectiveness of storytelling programs in improving, changing and correcting children's behavior as well as poor effects of other therapeutic methods, these programs are considered very important. Considering the previous results as well as the prevalence rates and adverse consequences of behavioral disorders in children, storytelling is regarded as an effective intervention in reducing children's social problems, aggressive behavior, and rule of law breaking behavior. In addition, with regard to the position of children as vital human capital, a major task of humanities researchers to investigate, analyze, and resolve the behavioral problems and disorders of children. Therefore, this study aimed to analyze the effect of storytelling on social problems, aggressive behavior, and rule of law breaking behavior of elementary school students. In other words, the study addressed the question whether storytelling would improve social problems, aggressive behavior, and rule of law breaking behavior among elementary school students. Accordingly, the authors proposed three hypotheses:

1- Storytelling has a significant, positive effect on social problems of elementary school students.

2- Storytelling reduces aggressive behavior of elementary school students.

3- Storytelling reduces rule of law breaking behavior of elementary school students.

\section{Material and Method}

A pretest-posttest design was employed to conduct this experimental study. Storytelling was considered the independent variable, whereas social problems, aggressive behavior, and rule of law breaking behavior were considered the dependent variables. The data were analyzed using descriptive statistics (mean and standard deviation) and inferential statistics (multivariate and univariate analysis of covariance).

\section{Statistical Population, Sample, and Sampling Method}

The statistical population consisted of all male and female students studying at an elementary school in Bandar Abbas in the academic year 2017-2018. According to their parents or teachers, the students suffered from emotional-behavioral problems (including social problems, aggressive behavior, and rule of law breaking behavior). The purposive sampling method was employed to select the children with emotional-behavioral problems. They were identified with the help of the parents or teachers completing the parent version of the CBCL. After an initial review of the completed forms, 43 students were identified with emotional-behavioral problems, and 30 students with the highest scores were selected and randomly divided into the experimental and control groups (15 participants per group). The students of the experimental group attended 15 sixty-minute storytelling sessions taught by two teachers, who were experienced in storytelling, as well as the mothers of some students. No intervention was applied to the members of the control group.

\section{Research Instrument}

The Child Behavior Checklist (CBCL) was developed by Achenbach and Rescorla (2001) based on DSM- 
III. This scale is employed to assess children's behavioral and mood status within the past six months. The checklist is completed by one of the parents or teachers who better knows a child. The scale consists of 115 three-choice items (score 0: never occurs; score 1: sometimes occurs; score 2: often or always occurs). This checklist measures 8 behavioral-emotional disorders, out of which only the following three components were assessed in this study:

A. Social Problems (SP).

B. Rule of Law Breaking Behavior (RB).

C. Aggressive Behavior (AG).

\section{Intervention}

The intervention instrument consisted of 15 illustrated stories (15 one-hour sessions) which were selected and partially modified by 6 experts with regard to the research objectives. Cartoons, animations, and audio stories were also presented in some sessions to help children better understand the stories. To actively engage children in the process, they were asked to express their views on each topic and solve puzzles and riddles included in some stories.

Table 1. An overview of the main topics of storytelling sessions

\begin{tabular}{|c|c|c|}
\hline Session & Topic & A summary of the intervention \\
\hline 1 & Introductory session & $\begin{array}{l}\text { Reviewing the objectives of the program, and providing children with some information } \\
\text { to actively participate in the storytelling sessions }\end{array}$ \\
\hline 2 & $\begin{array}{l}\text { How to start a conver- } \\
\text { sation }\end{array}$ & $\begin{array}{l}\text { Highlighting the importance of conversation, presenting an audio-visual program, and } \\
\text { encouraging active participation of participants }\end{array}$ \\
\hline 3 & $\begin{array}{l}\text { Conversation eti- } \\
\text { quette }\end{array}$ & Reviewing negotiation skills, and presenting audio-visual stories \\
\hline 4 & Self-awareness & $\begin{array}{l}\text { I can do it very well: It is the story of a boy named Jose who loves football but can't run } \\
\text { properly, so he has to find a way to reach his goal. By listening to this story, children will } \\
\text { learn how to make a balance between their positive and negative characteristics. }\end{array}$ \\
\hline 5 & Self-control & $\begin{array}{l}\text { New village: It is the story of a cold-hearted eagle who stoles a crow's chicks and head } \\
\text { for the mountains. }\end{array}$ \\
\hline 6 & Emotion management & Edison's life: This story helps children manage their emotions and acts to reach success. \\
\hline 7 & $\begin{array}{l}\text { Evaluation of previ- } \\
\text { ous sessions }\end{array}$ & Reviewing the content of previous sessions, and presenting several educational videos. \\
\hline 8 & Anger control & $\begin{array}{l}\text { Salad: It is the audio story of a hunter who helps a lonely old woman in the woods; the } \\
\text { story of an angry cat; the story of spring and rock }\end{array}$ \\
\hline 9 & Anger control & The story of anger; an educational video clip about anger control \\
\hline 10 & Respect for rules & The story of Noah \\
\hline 11 & $\begin{array}{l}\text { Evaluation and review } \\
\text { of previous sessions }\end{array}$ & Reviewing previous sessions \\
\hline 12 & Respect for rules & The story of Robin Hood \\
\hline 13 & Social skills & The story of three bad people and kind Matthew \\
\hline 14 & Social skills & The story of alliance of pigeons \\
\hline 15 & $\begin{array}{l}\text { Overall program eval- } \\
\text { uation }\end{array}$ & $\begin{array}{l}\text { A short animation about factors affecting an individual's success in life (stresses the im- } \\
\text { portance of social skills); thanking children for participating in the program }\end{array}$ \\
\hline
\end{tabular}




\section{Results}

MANCOVA was performed to analyze the effect of storytelling on emotional-behavioral problems among the participants. For this purpose, the students' pre-test and post-test scores were considered the control and dependent variables, respectively, whereas the group (experimental and control) variables were considered the independent variables. Table 2 shows the mean, standard deviation, skewness, and kurtosis of the research variables.

Table 2. Mean, standard deviation, skewness, and kurtosis of research variables

\begin{tabular}{|c|c|c|c|c|c|c|c|c|c|}
\hline \multirow{2}{*}{ Stage } & \multirow{2}{*}{ Variable } & \multicolumn{4}{c|}{ Experimental group } & \multicolumn{4}{c|}{ Control group } \\
\cline { 2 - 10 } & Social problems & $\overline{\mathrm{x}}$ & $\mathrm{SD}$ & Skewness & Kurtosis & $\overline{\mathrm{x}}$ & SD & Skewness & Kurtosis \\
\hline \multirow{3}{*}{ Pre-test } & 10.53 & 3.20 & 0.14 & -0.46 & 15.07 & 2.15 & 0.30 & -1.66 \\
\cline { 2 - 11 } & Rule of law breaking behavior & 9.60 & 3.09 & 0.37 & -0.61 & 21.80 & 2.40 & -0.34 & -1.36 \\
\cline { 2 - 11 } & Aggressive behavior & 11.60 & 3.66 & -0.41 & -0.76 & 21.47 & 3.14 & -1.91 & 5.90 \\
\hline \multirow{3}{*}{ Post-test } & Social problems & 8.67 & 2.35 & 0.16 & -0.53 & 9.73 & 2.74 & 1.05 & 2.90 \\
\cline { 2 - 10 } & Rule of law breaking behavior & 6.73 & 2.76 & 1.51 & 2.21 & 15.13 & 2.59 & 0.52 & 0.47 \\
\cline { 2 - 10 } & Aggressive behavior & 8.53 & 2.85 & 0.46 & 0.34 & 15.13 & 4.09 & -0.49 & -0.78 \\
\hline
\end{tabular}

$(\overline{\mathrm{x}}=$ mean $)$

Based on the above table, the mean scores obtained for those in the experimental group were lower than the control group members regarding the components of social problems, rule of law breaking behavior, and aggressive behavior. The researchers first tested the main assumptions of MANCOVA, and it was later performed to analyze the significance of the differences. Levene's test, Kolmogorov-Smirnov test, and interaction effect of pre-test scores, and independent variables were utilized to assess the equality of variances, normal distribution of variables, and homogeneity of regression slopes, respectively. Table 3 presents the results of Levene's test. According to the table 3, the assumption of equality of variances is confirmed for all three variables. The results of Kolmogorov-Smirnov normality test are presented in the table 4.

Table 3. Results of Levene's test for equality of variances

\begin{tabular}{|l|l|l|l|l|}
\hline Variable & F & Df1 & Df2 & P \\
\hline Social problems & 0.04 & 1 & 28 & 0.84 \\
\hline Rule of law breaking behavior & 0.01 & 1 & 28 & 0.93 \\
\hline Aggressive behavior & 3.65 & 1 & 28 & 0.07 \\
\hline
\end{tabular}

Table 4. Results of Kolmogorov-Smirnov normality test

\begin{tabular}{|l|l|l|l|l|}
\hline Variable & Group & Statistic & Df & P \\
\hline \multirow{2}{*}{ Social problems } & Control & 0.15 & 15 & 0.20 \\
\cline { 2 - 5 } & Experimental & 0.19 & 15 & 0.16 \\
\hline \multirow{2}{*}{ Rule of law breaking behavior } & Control & 0.21 & 15 & 0.09 \\
\cline { 2 - 5 } & Experimental & 0.13 & 15 & 0.20 \\
\hline \multirow{2}{*}{ Aggressive behavior } & Control & 0.16 & 15 & 0.20 \\
\cline { 2 - 5 } & Experimental & 0.12 & 15 & 0.20 \\
\hline
\end{tabular}

According to the table 4, the assumption of normality of the distribution is confirmed for the three research variables. To assess the homogeneity of the regression slopes, the interaction effect of pre-test scores and 
independent variables on post-test scores were assessed. As shown in Table 5, the interaction effect was not significant; therefore, the assumption was confirmed for all three variables.

Table 5. Homogeneity of regression slopes assumption

\begin{tabular}{|l|l|l|l|l|l|l|}
\hline Source of variance & Dependent variable & SS & DF & MS & F & P \\
\hline \multirow{3}{*}{$\begin{array}{l}\text { Interaction effect of pre-test scores and independent } \\
\text { variables }\end{array}$} & Social problems & 3.61 & 1 & 3.61 & 0.55 & 0.46 \\
\cline { 2 - 7 } & Rule of law breaking behavior & 0.35 & 1 & 0.35 & 0.05 & 0.82 \\
\cline { 2 - 7 } & Aggressive behavior & 7.76 & 1 & 7.76 & 0.80 & 0.38 \\
\hline
\end{tabular}

Box's M-test value (5.92) was also calculated to check the equality of multiple variance-covariance matrices $(\mathrm{P}$-value $=0.52)$. Table 6 shows the results of MANCOVA performed to compare participants in the experimental and control groups in terms of emotional-behavioral problems.

Table 6. MANCOVA conducted for analyzing the effect of storytelling on students' emotional-behavioral problems

\begin{tabular}{|c|c|c|c|c|c|c|c|}
\hline Source of variance & Dependent variable & SS & DF & MS & $\mathbf{F}$ & $\mathbf{P}$ & $\eta^{2}$ \\
\hline \multirow{3}{*}{ Pre-test } & Social problems & 9.14 & 1 & 9.14 & 1.43 & 0.24 & 0.05 \\
\hline & Rule of law breaking behavior & 20.65 & 1 & 20.65 & 3.10 & 0.09 & 0.10 \\
\hline & Aggressive behavior & 88.84 & 1 & 88.84 & 9.28 & $0 / 01$ & $0 / 26$ \\
\hline \multirow{3}{*}{ Intergroup } & Social problems & 2.48 & 1 & 2.48 & 0.39 & 0.54 & 0.01 \\
\hline & Rule of law breaking behavior & 27.03 & 1 & 27.03 & 4.05 & 0.05 & 0.13 \\
\hline & Aggressive behavior & 1.60 & 1 & 1.60 & 0.17 & 0.69 & 0.01 \\
\hline \multirow{3}{*}{ Intragroup } & Social problems & 173.12 & 27 & 6.41 & & & \\
\hline & Rule of law breaking behavior & 180.02 & 27 & 6.67 & & & \\
\hline & Aggressive behavior & 258.62 & 27 & 9.58 & & & \\
\hline \multirow{3}{*}{ Total } & Social problems & 190.80 & 29 & & & & \\
\hline & Rule of law breaking behavior & 729.87 & 29 & & & & \\
\hline & Aggressive behavior & 674.17 & 29 & & & & \\
\hline
\end{tabular}

As shown in the table 6, there was a significant difference between the experimental and control groups only in rule of law breaking behavior, whereas no significant difference was observed between these groups in terms of social problems and aggressive behavior. Table 2 also showed that the mean score of the experimental group was lower than that of the control group in the component of rule of law breaking behavior. In addition, the partial eta squared values showed that storytelling explained $13 \%$ of variance of the rule of law breaking behavior.

\section{Discussion}

This study analyzed the effectiveness of storytelling sessions in reducing social problems, aggressive behavior, and rule of law breaking behavior among a group of elementary school students. The results indicated that children who participated in storytelling sessions had fewer social problems and displayed aggressive and rule of law breaking behavior less often than those in the control group. There was a significant difference between the experimental and control groups only in rule of law breaking behavior, whereas no significant difference was observed between them in terms of social problems and aggressive behavior. This finding is inconsistent with the findings of Gonçalves et al. (2017) who found that storytelling reduced aggression among preschool children but had no significant effect on rule of law breaking behavior. In this regard, it is safe to state that 
behavioral problems are caused by the interaction of a wide range of biological, emotional, and psychosocial variables. Individual differences can cause, accelerate, and perpetuate behavioral problems and disorders. Emotional-psychological environments of families and the way children interact with external settings and peers can significantly affect their reactions to corrective programs. Several factors, influenced by individual differences, determine the effectiveness of behavior intervention programs; therefore, storytelling reduces aggressive behavior effectively among some children, although it has no significant effect on others. Furthermore, according to some biological theories, aggression can result partially from biological and instinctive factors that may not be significantly influenced by external training.

Some of the present findings are in line with the findings of (Roshan Chesli, 2012), (Gonçalves et al., 2017), (Nasirzadeh \& Roshan, 2010), (Patel \& Patel, 2017) and Burgess (2006). These studies generally indicate that enhancing social skills and establishing suitable interactions are the most important strategies for correcting the behavior of children with behavioral-emotional disorders. At the same time, due to the special behavior and personality traits of this group of children, they rarely accept direct instructions and guidance; thus, it is difficult to directly teach them appropriate cognitive and social skills. Therefore, indirect techniques such as storytelling open up a window into these children's intrinsic world. Such methods can also stimulate the feelings and perceptions of these children, and thereby enrich their experiences, increase their trust, and lay the foundations for their positive relationships with adults and peers.

Burgess (2006) found that the enchanting atmosphere of a story prepares children to hear and understand various events and messages in a space free of fear, humiliation, violence, and anger. The present results are also consistent with those obtained by Haigh and Hardy (2011). According to their study, storytelling can play a positive role in encouraging children to display reasonable and lawful behavior by influencing their personality and mental health. In other words, recommendations and guidance within stories slowly penetrate children's personality and behavior and help them establish appropriate interactions with others. As a result, children will receive positive feedback from others, something which will increase their confidence, sense of self-worth, self-awareness, and self-control.

Some results of this study are consistent with the findings of Teglasi and Rothman (2001) who found that storytelling served as a beneficial technique to reduce students' communicational and social problems in classrooms. Some findings are also in line with the findings of Gonçalves et al. (2017), who concluded that stories helped a narrator establish an emotional bond with listeners. This experience can reduce aggressive behavior in children. Stories here serve as bridges used by the storyteller to influence children and to encourage them to make decisions which will lead to positive behavioral outcomes. Finally, it is fair to conclude that stories familiarize some children with new experiences and teach them different social, moral, and emotional norms.

\section{Declaration of Conflicting Interests}

The author(s) declared no potential conflicts of interest with respect to the research, authorship, and/or publication of this article.

Funding: The author(s) received no financial support for the research, authorship, and/or publication of this article.

Acknowledgements: The authors would like to thank all the esteemed parents, teachers, and students for their sincere cooperation and companionship until the end of this storytelling project. 


\section{References}

Abaresi, R., \& Temuri, S. (2015). The effect of storytelling and role playing on learning social skills by teachable mentally retarded children. Scientific Journal of Education Research, 7(31), 1-18.

Burgess, J. (2006). Hearing ordinary voices: Cultural studies, vernacular creativity and digital storytelling. Continuum, 20(2), 201-214.

Fallahnejad, M., Kazemi, F., \& Pezeshk, S. (2018). Effectiveness of Visual Storytelling on the Reduction of Externalizing and Internalizing Behaviors in Children with Oppositional Defiant Disorder. Journal of Exceptional Children, 17(3), 5-18.

Gamarigivi, H., \& Khoshnoodnia, B. (2016). Comparison of social skills, mental health and academic performance in children with divorced, divorcing and intact parents. Journal of Family Research, 12(45), 69-92.

Gonçalves, L. L., Voos, M. C., Almeida, M. H. M. d., \& Caromano, F. A. (2017). Massage and storytelling reduce aggression and improve academic performance in children attending elementary school. Occupational therapy international, 2017.

Haigh, C., \& Hardy, P. (2011). Tell me a story - a conceptual exploration of storytelling in healthcare education. Nurse Education Today, 31(4), 408-411.

Rozdar, E., Naziri, G., \& Hosseini, S. (2014). Effectiveness of Storytelling Therapy on the Reduction of Aggression and Stubbornness in Children with Oppositional Defiant Disorder. Zahedan J Res Med Sci, 16(9), 83-85.

Margalit, M. (2010). Lonely children and adolescents: Self-perceptions, social exclusion, and hope. Springer Science \& Business Media.

Musavi, Z., \& Hejazi, M. (2016). Effectiveness of Narrative Therapy in Reducing Aggression and Stubborn Preschoolers. Electronic J Biol, 12(2).

Nasirzadeh, R., \& Roshan, R. (2010). The effect of storytelling on aggression in six to eight-year old boys. Iranian Journal of Psychiatry and Clinical Psychology, 16(2), 118-126.

Oduolowu, E., \& Oluwakemi, E. (2014). Effect of storytelling on listening skills of primary one pupil in Ibadan north local government area of Oyo state, Nigeria. International Journal of Humanities and Social Science, 4(9), 100-107.

Patel, N., \& Patel, N. (2017). Modern technology and its use as storytelling communication strategy in public health. MOJ Public Health, 6(3), 00171.

Roshan Chesli, R. (2012). The Effect of Storytelling Based on Social Skills Training on Improving Social Skills and Behavioral Problems in 8-10 Year-Old Boy Students with Opiate and Disorder (ODD) Disorders. Quarterly Clinical Psychology, 3(9), 73-93.

Sylvers, P. D., Brennan, P. A., \& Lilienfeld, S. O. (2011). Psychopathic traits and preattentive threat processing in children: a novel test of the fearlessness hypothesis. Psychological Science, 22(10), 1280-1287.

Teglasi, H., \& Rothman, L. (2001). Stories a classroom-based program to reduce aggressive behavior. Journal of School Psychology, 39(1), 71-94.

Watts, K. S. (2008). The effectiveness of a social story intervention in decreasing disruptive behavior in autistic children. (Phd), The Ohio State University.

Wright, C., Diener, M. L., \& Kemp, J. L. (2013). Storytelling dramas as a community building activity in an early childhood classroom. Early Childhood Education Journal, 41(3), 197-210.

YavandHasani, A., Farahbakhsh, K., \& ShafiAbadi, A. (2014). Effectiveness of Cognitive-Behavioral Therapy on the Treatment of Adolescent Behavioral Disorders. Journal of Clinical Psychology and Research, 4(7), 71-94. 